\title{
Low myelinated nerve-fibre density may lead to symptoms associated with nerve entrapment in vibration-induced neuropathy
}

\author{
Lars B Dahlin ${ }^{1,3^{*}}$, Helena Sandén², Erik Dahlin', Malin Zimmerman', Niels Thomsen ${ }^{1}$ and Anders Björkman
}

\begin{abstract}
Prolonged exposure to hand-held vibrating tools may cause a hand-arm vibration syndrome (HAVS), sometimes with individual susceptibility. The neurological symptoms seen in HAVS are similar to symptoms seen in patients with carpal tunnel syndrome (CTS) and there is a strong relationship between CTS and the use of vibrating tools. Vibration exposure to the hand is known to induce demyelination of nerve fibres and to reduce the density of myelinated nerve fibres in the nerve trunks. In view of current knowledge regarding the clinical effects of low nerve-fibre density in patients with neuropathies of varying aetiologies, such as diabetes, and that such a low density may lead to nerve entrapment symptoms, a reduction in myelinated nerve fibres may be a key factor behind the symptoms also seen in patients with HAVS and CTS. Furthermore, a reduced nerve-fibre density may result in a changed afferent signal pattern, resulting in turn in alterations in the brain, further prompting the symptoms seen in patients with HAVS and CTS. We conclude that a low nerve-fibre density lead to symptoms associated with nerve entrapment, such as CTS, in some patients with HAVS.
\end{abstract}

Keywords: Vibration exposure, Nerve compression, Carpal tunnel syndrome, Neuropathy, Cerebral plasticity

\section{Vibration exposure and HAVS}

Prolonged exposure to hand-held vibrating tools, which are commonly used in several occupations, may lead to a variety of disorders in the vascular, neural, and musculoskeletal systems. These conditions are collectively known as the hand-arm vibration syndrome (HAVS). Workers exposed to hand-arm vibration may experience tingling and numbness in their fingers and hands and, if such exposure continues, may develop a reduction in perception regarding touch and temperature. Moreover, and crucial from a functional point of view, prolonged exposure eventually leads to impairment of manual dexterity impacting on the patients' professional life and leisure activities and consequently a lower quality of life [1-3]. Within the Swedish workforce, $15 \%$ of employed men and $3 \%$ of employed women use hand-held vibrating tools for at least 25\% of their workday (Statistics Sweden, 2011)

\footnotetext{
* Correspondence: lars.dahlin@med.lu.se

'Department of Hand Surgery, Lund University, Skåne University Hospital, Malmö, Sweden

${ }^{3}$ Department of Clinical Sciences in Malmö, Hand Surgery, Lund University, Jan Waldenströms gata 5, SE-205 02 Malmö, Sweden

Full list of author information is available at the end of the article
}

[4]. However, the true prevalence of exposure to handheld vibrating tools is difficult to assess and depends on the population studied. A recent review concluded that there is substantial evidence of a dose-response relationship between vibration exposure and HAVS [5].

\section{Nerve compression and HAVS}

Among nerve entrapments, carpal tunnel syndrome (CTS) is by far the most common, affecting $3-4 \%$ of the general population and with a high rate of surgical intervention [6,7]. The majority of CTS cases are considered to be idiopathic, but there are many known risk factors, such as diabetes, hypothyroidism and vibration exposure. From a clinical point of view, there is an individual vulnerability to peripheral neuropathy and/or CTS following exposure to hand-held vibrating tools. The neurological symptoms of HAVS are similar to the symptoms found in CTS, which makes it difficult to distinguish between the two conditions. Patients with CTS may also experience symptoms from the fingers innervated by the ulnar nerve, which add to the difficulties of making a proper diagnosis [8]. Furthermore, 
standard clinical testing, such as that for perception of touch, may demonstrate similar results for the two conditions. However, refined diagnostic tests, such as electrophysiology and tactilometry [9-11], allow a distinction to be made between pathology located specifically to the median nerve and/or in the ulnar nerve or a general neuropathy, such as HAVS. Thus, these diagnostic tests may assist in differentiating between CTS and HAVS. A difference in the susceptibility of neuropathy between the median and ulnar nerves has also been detected in some conditions, such as type 2 diabetes [12].

The diagnosis of HAVS, and particularly the peripheral neuropathy seen in HAVS, is largely based on the patient's own history of symptoms and duration of exposure to hand-held vibrating tools in combination with clinical examination and a variety of sensory tests. There is no single diagnostic test specific for HAVS. Some of the tests used are quantitative sensory tests, e.g. the vibration threshold test and tests for thermal perception and perception threshold with monofilaments [13]. They are all so-called psychophysical tests, since their outcome, which depends on the integrity of the entire somatosensory pathway, is based on an objective physical stimulus that relies on a subjective response from the tested individual. The only objective sensori-neural test to diagnose large-fibre neuropathy is the nerve conduction test, but this measures only the function of the fastest conducting myelinated nerve fibres. Thus, in fact, just a limited proportion of the whole nerve fibre population is available for testing. Nonetheless, the electrophysiology test is considered to be the gold standard for the diagnosis of nerve entrapment, such as CTS, as fractionated nerve conduction testing with measurement of conduction velocity and amplitude [14] across the carpal tunnel provides sufficient sensitivity and specificity for the diagnosis. However, the results from the electrophysiology test should always be related to the patient's symptoms and clinical signs at investigation before a definitive diagnosis is set.

Occupational hand-arm-vibration exposure and forceful repetitive workload are known risk factors for CTS [5,15-20]. A recent meta-analysis shows a strong relationship between a stringent case definition of CTS (symptoms combined with nerve conduction abnormality) and the use of vibratory tools (OR 5.40; 95\% CI 3.14 - 9.31), hand force (OR 4.23; 95\% CI 1.53, 11.68) and repetitive hand use (OR 2.26; 95\% CI 1.73, 2.94) [15]. A better understanding of the factors that may explain individual vulnerability to CTS and neuropathy following exposure to hand-held vibrating tools would provide better treatment possibilities. Furthermore, it would also enhance our ability to advise the patient regarding future exposure to hand-arm vibration. Here, we present current knowledge concerning nerve-fibre density in neuropathies of various origins, focusing on vibration-induced neuropathy, and its relation to symptoms of CTS. Our hypothesis is that low nerve-fibre density may lead to symptoms associated with nerve entrapment. Furthermore, changes in nerve-fibre density may also result in a change in afferent nerve signal pattern, which in turn results in alterations in the central nervous system (CNS). These cerebral changes may further potentiate the symptoms seen in patients with HAVS and CTS. Finally, we will briefly describe techniques that may be of value in the diagnosis of nerve dysfunction in HAVS with and without CTS.

\section{Nerve compression and neuropathy}

Changes in peripheral nerves due to compression experimental studies

The pathophysiology of nerve entrapments is complex as it affects all structures in and around the peripheral nerve. The response to compression can be summarized as a combination of disturbance in the intraneural microcirculation, increased vascular permeability, formation of endoneurial oedema, increased endoneurial fluid pressure, demyelination, induction of inflammation, axonal degeneration, fibrosis, new axonal growth, remyelination as well as perineurial and endothelial thickening [21,22]. These responses depend on the nature, magnitude and duration of compression and the coexistence of other diseases, such as diabetes. The most important components in a peripheral nerve trunk, i.e. the axons, respond differently depending on their size. Furthermore, animal experiments have shown that the Schwann cells around the axons also are affected by the compression. Experimental studies have shown that the response is more pronounced in both neurons and Schwann cells in diabetic animals than in healthy ones [23]. The intracellular transport in the axon, i.e. axonal transport, provides the distal part of the nerve with essential substances as well as conveying information from the periphery up to the nerve-cell body. Axonal transport is also more severely inhibited in the sciatic nerve in diabetic rats during compression. Concerning individual nerve fibres, it has been reported from animal studies that large myelinated nerve fibres become demyelinated and degenerate early during nerve compression, while the non-myelinated nerve fibres withstand higher levels of compression and for longer time periods [24-26]. Thus, from a neurobiological standpoint there is supporting evidence that large myelinated nerve fibres are more susceptible to compression than non-myelinated nerve fibres.

\section{Findings in nerve biopsies from humans}

There is limited knowledge concerning the impact of nerve-fibre density as a risk factor in the development of peripheral neuropathy or nerve entrapment symptoms 
in humans [27]. However, there are indications that a low axonal density may lead to neuropathy $[28,29]$. To assess nerve-fibre density, a relevant nerve biopsy is required, but potential complications mean that diagnostic nerve biopsies are rarely performed; leading to limited research being done in this field. Recently, we reported that the number of myelinated nerve fibres can be quantified from biopsies of the terminal branch of the posterior interosseus nerve taken from the dorsum of the wrist, at the same level as the median nerve in the carpal tunnel [29]. The risk of complications after such a procedure is low [28-30] in contrast to "classic" sural nerve biopsies [31-33]. In patients with CTS with no other neuropathy, a significant reduction in myelinated nerve fibres and endoneurial capillary densities was found compared to healthy subjects without CTS [29]. More importantly, it was also demonstrated that the decreased myelinated nerve-fibre density was even more accentuated in patients with diabetes and CTS. Thus, a nerve trunk that is not exposed to compression in a diabetic patient demonstrates a reduction in myelinated nerve fibre and endoneurial capillary densities. If these findings from the posterior interosseus nerve are extrapolated to the closely located median nerve, a general hypoxic environment due to reduced vascularity as well as a reduction in nerve-fibre density could predispose to nerve compression symptoms from the median nerve [28].

\section{Nerve structure and dysfunction}

A number of studies have examined the relation between results from nerve biopsies and clinical nerve dysfunction. A significant association between a reduced myelinated nerve-fibre density, clinical signs of neuropathy and electrophysiological dysfunction was demonstrated from sural nerve biopsies in subjects with diabetes, those with impaired glucose tolerance, and those with normal glucose tolerance [34-36]. Furthermore, a correlation was also found between low myelinated nerve-fibre density and progression of nerve dysfunction. These results indicate that a low myelinated nerve-fibre density presents clinically as neuropathy $[37,38]$. However, the fibre density does not correlate with the glucose-tolerance status, i.e. level of blood glucose, indicating that factors other than the blood glucose level also influence the development of neuropathy. Normal aging affects the nervous system with a progressive reduction in neurons and axons, making the peripheral nerve even more susceptible, probably more so in nerves affected by a concomitant disease, such as diabetes. Therefore, even healthy subjects with already low myelinated nerve-fibre density may be unable to compensate for the normal effect of aging and are thus more prone to develop nerve dysfunction when the nerve is compressed.

\section{Effects of vibration exposure on nerve fibres}

The pathophysiology of vibration-induced neuropathy is complex, but includes morphological changes, such as degeneration of nerve fibres and fibrosis [39,40]. Strömberg et al reported pathological changes in biopsies from the posterior interosseus nerve in patients exposed to vibration, and concluded that demyelination might be the primary lesion in neuropathy following vibration exposure [40]. They also demonstrated that demyelination was followed by oedema, endoneurial fibrosis and, in some cases, even axonal degeneration. This agrees with the findings of $\mathrm{Ho}$ and $\mathrm{Yu}$ [41] who exposed rabbits to vibration and showed that "destruction of the myelin sheath occurs earlier, more severely, and more frequently than that of the axon". Similar studies performed on rats [42-44], simulating vibration from hand-held power tools, reported axonal damage and myelin fragmentation in nerves that had been exposed to vibration, explaining the observed increased stress response in the vibrationexposed rat nerves [45].

\section{Electrophysiological changes in HAVS and CTS}

Electrophysiological studies, designed to explain the nature of the nerve injury in HAVS, have provided inconsistent results [9,10,46-48]. Most studies show a reduction in conduction velocity, indicating demyelination, of the fastest large myelinated fibres and in later stages, when the patients have more pronounced symptoms, a lower amplitude, indicating a loss of nerve fibres [48]. The abnormalities, independent of clinical symptoms of entrapment, extended from a distally reduced sensory nerve conduction localized to the digits $[49,50]$ to signs of median and ulnar neuropathies proximal to the hand as well as an association with CTS [51-53]. It is important that the electrophysiological examination is done properly [54-56]. Examination of fractionated nerve conduction of the median nerve across the carpal tunnel [14] in vibration-exposed subjects has revealed a bimodal velocity distribution; thus, one group of patients had a significant reduction in conduction velocity, similar to that seen in idiopathic carpal tunnel syndrome, while another group had no signs of nerve compression at the carpal tunnel, suggesting more distal dysfunction at the level of palm or finger, or at the receptor level [9]. Furthermore, distal motor latency at the wrist is an additional variable that can be measured, where it is longer in patients with CTS. Rosen et al [9] also show that patients exposed to vibration have pronounced increased vibration thresholds in the fingers. Taken together, these results imply that a thorough history taken from the patients, as well as that a careful clinical examination and a meticulous electrophysiological examination, also using tactilometry, are essential components in the diagnostic work-up $[10,11]$. 


\section{Outcome of surgery for CTS in HAVS}

The outcome of surgery for CTS seems to be less favourable in patients with vibration-induced neuropathy [57-59]. Patients with HAVS may primarily have injuries/alterations in peripheral sensory receptors, large or thin myelinated nerve fibres, and the small-calibre nonmyelinated C-fibres with only few patients having additional symptoms of CTS [15]. Thus, a carpal tunnel release operation may not result in symptom relief. As pointed out earlier, the decision to perform surgery on patients with HAVS and a suspicion of CTS requires careful consideration, with adequate preoperative examinations, and the provision of meticulous preoperative information for the patients, similar to the treatment strategies for patients with diabetes and CTS [8].

\section{Cerebral changes after a nerve injury}

Finally, when discussing the complex pathophysiology of neuropathy and CTS in HAVS one should also consider the potential effects on the central nervous system. It is well known that a peripheral nerve injury in the form of a transection or a vibration-induced neuropathy leads to changes in the brain $[60,61]$. The signal pattern from the injured nerve to the brain is altered, resulting in a reorganisation in the cerebral areas processing sensory information from the hand. The possibilities of interpreting the new signal pattern from the injured nerve are dependent on several factors, where age and higher cognitive functioning are important for the functional outcome. Furthermore, as sensory information is crucial for optimal motor control, a disturbance in afferent nerve impulses from the hand results in disturbed muscle function in the hand. Thus, the mechanisms behind the clinical outcome following HAVS are likely to be found both in the peripheral (PNS) and in the central nervous systems (CNS).

\section{Conclusion}

We conclude that a) hand-arm vibration exposure is associated with an increased risk of CTS; b) hand-arm vibration exposure appears to be associated with diffuse demyelination of nerves in the hand/wrist area and later a reduction in the myelinated nerve fibers and c) these structural changes, seen particularly as a low myelinated nerve-fibre density, may lead to symptoms associated with nerve entrapment, in particular CTS. Thus, a mechanism, based on a low myelinated nerve-fibre density similar to that observed in healthy and diabetic subjects with CTS, may also be present in HAVS. A peripheral neuropathy also results in a cerebral reorganisation. Thus, the clinical symptoms seen in these patients are caused by changes both in the peripheral and central nervous systems. Patients with HAVS and clinical symptoms of CTS should be carefully considered for surgery since the outcome is not always favourable. Patients with HAVS and a suspicion of CTS should be evaluated, through a thorough patient history, careful clinical examination and appropriate blood samples to exclude other causes of neuropathy. Furthermore, a complete electrophysiological examination, including fractionated nerve conduction of the median nerve across the carpal tunnel, and a tactilometry should be performed.

\section{Abbreviations \\ CTS: Carpal tunnel syndrome; HAVS: Hand-arm vibration syndrome; CNS: Central nervous system; PNS: Peripheral nervous system.}

\section{Competing interests}

The authors declare that they have no competing interests.

\section{Authors' contributions}

All authors have contributed equally to the production of the manuscript. All authors read and approved the final manuscript.

\section{Acknowledgements}

The authors are members of VIBNET; a network of researchers in the field of vibration-induced injuries.

\section{Fundings}

The research that is referenced from our group is funded by the Research Council (Medicine), Swedish Diabetes Association, Malmö Diabetesförening, Region Skåne, Promobilia, Swedish Society of Medicine, Skåne University Hospital and Lund University.

\section{Author details}

'Department of Hand Surgery, Lund University, Skåne University Hospital, Malmö, Sweden. 'Department of Occupational and Environmental Medicine, Sahlgrenska School of Public Health and Community Medicine, University of Gothenburg, Gothenburg, Sweden. ${ }^{3}$ Department of Clinical Sciences in Malmö, Hand Surgery, Lund University, Jan Waldenströms gata 5, SE-205 02 Malmö, Sweden.

Received: 30 October 2013 Accepted: 3 March 2014

Published: 8 March 2014

\section{References}

1. Cederlund R, Nordenskiold U, Lundborg G: Hand-arm vibration exposure influences performance of daily activities. Disabil Rehabil 2001, 23:570-577.

2. Carlsson I: Cold sensitivity in injured and normal hands. Consequences for daily life, Dissertation. Lund University, Faculty of Medicine; 2010.

3. Cederlund R, Iwarsson S, Lundborg G: Quality of life in Swedish workers exposed to hand-arm vibration. Occup Ther Int 2007, 14:156-169.

4. Swedish Work Environment Authority: Arbetsmiljön 2011. In: Arbetsmiljöstatistik Rapport. Stockholm; 2012 (http://www.av.se/dokument/ statistik/officiell_stat/ARBORS2012.pdf).

5. Heaver C, Goonetilleke KS, Ferguson H, Shiralkar S: Hand-arm vibration syndrome: a common occupational hazard in industrialized countries. J Hand Surg Eur Vol 2011, 36:354-363.

6. Atroshi I, Gummesson C, Johnsson R, Ornstein E, Ranstam J, Rosen I: Prevalence of carpal tunnel syndrome in a general population. JAMA 1999, 282:153-158.

7. Atroshi I, Englund M, Turkiewicz A, Tagil M, Petersson IF: Incidence of physician-diagnosed carpal tunnel syndrome in the general population. Arch Intern Med 2011, 171:943-944.

8. Thomsen NO, Cederlund R, Rosen I, Bjork J, Dahlin LB: Clinical outcomes of surgical release among diabetic patients with carpal tunnel syndrome: prospective follow-up with matched controls. J Hand Surg [Am] 2009, 34:1177-1187.

9. Rosen I, Stromberg T, Lundborg G: Neurophysiological investigation of hands damaged by vibration: comparison with idiopathic carpal tunnel syndrome. Scand J Plast Reconstr Surg Hand Surg 1993, 27:209-216. 
10. Stromberg T, Dahlin LB, Rosen I, Lundborg G: Neurophysiological findings in vibration-exposed male workers. J Hand Surg (Br) 1999, 24:203-209.

11. Stromberg T, Dahlin LB, Lundborg G: Vibrotactile sense in the hand-arm vibration syndrome. Scand J Work Environ Health 1998, 24:495-502

12. Dahlin LB, Thrainsdottir S, Cederlund R, Thomsen NO, Eriksson KF, Rosen I, Speidel T, Sundqvist G: Vibrotactile sense in median and ulnar nerve innervated fingers of men with Type 2 diabetes, normal or impaired glucose tolerance. Diabet Med 2008, 25:543-549.

13. Chong PS, Cros DP: Technology literature review: quantitative sensory testing. Muscle Nerve 2004, 29:734-747.

14. Ross MA, Kimura J: AAEM case report \#2: the carpal tunnel syndrome. Muscle Nerve 1995, 18:567-573.

15. Barcenilla A, March LM, Chen JS, Sambrook PN: Carpal tunnel syndrome and its relationship to occupation: a meta-analysis. Rheumatology (Oxford) 2012, 51:250-261.

16. Ibrahim I, Khan WS, Goddard N, Smitham P: Carpal tunnel syndrome: a review of the recent literature. Open Orthop J 2012, 6:69-76.

17. Palmer KT, Harris EC, Coggon D: Carpal tunnel syndrome and its relation to occupation: a systematic literature review. Occup Med (Lond) 2007. 57:57-66.

18. Palmer KT: Carpal tunnel syndrome: the role of occupational factors. Best Pract Res Clin Rheumatol 2011, 25:15-29.

19. Shiri R, Miranda H, Heliovaara M, Viikari-Juntura E: Physical work load factors and carpal tunnel syndrome: a population-based study. Occup Environ Med 2009, 66:368-373.

20. Falkiner S: Diagnosis and treatment of hand-arm vibration syndrome and its relationship to carpal tunnel syndrome. Aust Fam Physician 2003, 32:530-534.

21. Keir PJ, Rempel DM: Pathomechanics of peripheral nerve loading. Evidence in carpal tunnel syndrome. J Hand Ther 2005, 18:259-269.

22. Rempel D, Dahlin L, Lundborg G: Pathophysiology of nerve compression syndromes: response of peripheral nerves to loading. J Bone Joint Surg Am 1999, 81:1600-1610.

23. Dahlin LB, Stenberg $L$, Luthman $H$, Thomsen NO: Nerve compression induces activating transcription factor 3 in neurons and Schwann cells in diabetic rats. Neuroreport 2008, 19:987-990.

24. Shyu BC, Danielsen N, Andersson SA, Dahlin LB: Effects of sympathetic stimulation on C-fibre response after peripheral nerve compression: an experimental study in the rabbit common peroneal nerve. Acta Physiol Scand 1990, 140:237-243.

25. Dahlin LB, Shyu BC, Danielsen N, Andersson SA: Effects of nerve compression or ischaemia on conduction properties of myelinated and non-myelinated nerve fibres. An experimental study in the rabbit common peroneal nerve. Acta Physiol Scand 1989, 136:97-105.

26. Mosconi T, Kruger L: Fixed-diameter polyethylene cuffs applied to the rat sciatic nerve induce a painful neuropathy: ultrastructural morphometric analysis of axonal alterations. Pain 1996, 64:37-57.

27. Thomas PK, Fullerton PM: Nerve fibre size in the carpal tunnel syndrome. J Neurol Neurosurg Psychiatry 1963, 26:520-527.

28. Thomsen NO, Mojaddidi M, Malik RA, Dahlin LB: Reduced myelinated nerve fibre and endoneurial capillary densities in the forearm of diabetic and non-diabetic patients with carpal tunnel syndrome. Acta Neuropathol 2009, 118:785-791.

29. Thomsen NO, Mojaddidi M, Malik RA, Dahlin LB: Biopsy of the posterior interosseous nerve: a low morbidity method for assessment of peripheral nerve disorders. Diabet Med 2009, 26:100-104.

30. Richards TA, Curtin CM: Posterior interosseous nerve: an alternative to sural nerve biopsy. Plast Reconstr Surg 2010, 126:213e-214e.

31. Dahlin LB, Eriksson KF, Sundkvist G: Persistent postoperative complaints after whole sural nerve biopsies in diabetic and non-diabetic subjects. Diabet Med 1997, 14:353-356

32. Perry JR, Bril V: Complications of sural nerve biopsy in diabetic versus non-diabetic patients. Can J Neurol Sci 1994, 21:34-37.

33. Solders G: Discomfort after fascicular sural nerve biopsy. Acta Neurol Scand 1988, 77:503-504.

34. Malik RA, Veves A, Walker D, Siddique I, Lye RH, Schady W, Boulton AJ: Sural nerve fibre pathology in diabetic patients with mild neuropathy: relationship to pain, quantitative sensory testing and peripheral nerve electrophysiology. Acta Neuropathol 2001, 101:367-374.

35. Veves A, Malik RA, Lye RH, Masson EA, Sharma AK, Schady W, Boulton AJ: The relationship between sural nerve morphometric findings and measures of peripheral nerve function in mild diabetic neuropathy. Diabet Med 1991, 8:917-921.

36. Thrainsdottir S, Malik RA, Rosen I, Jakobsson F, Bakhtadze E, Petersson J, Sundkvist G, Dahlin LB: Sural nerve biopsy may predict future nerve dysfunction. Acta Neurol Scand 2009, 120:38-46.

37. Eriksson KF, Nilsson H, Lindgarde F, Osterlin S, Dahlin LB, Lilja B, Rosen I, Sundkvist G: Diabetes mellitus but not impaired glucose tolerance is associated with dysfunction in peripheral nerves. Diabet Med 1994, 11:279-285.

38. Sundkvist G, Dahlin LB, Nilsson H, Eriksson KF, Lindgarde F, Rosen I, Lattimer SA, Sima AA, Sullivan K, Greene DA: Sorbitol and myo-inositol levels and morphology of sural nerve in relation to peripheral nerve function and clinical neuropathy in men with diabetic, impaired, and normal glucose tolerance. Diabet Med 2000, 17:259-268.

39. Takeuchi T, Futatsuka M, Imanishi H, Yamada S: Pathological changes observed in the finger biopsy of patients with vibration-induced white finger. Scand J Work Environ Health 1986, 12:280-283.

40. Stromberg T, Dahlin LB, Brun A, Lundborg G: Structural nerve changes at wrist level in workers exposed to vibration. Occup Environ Med 1997 54:307-311

41. Ho ST, Yu HS: Ultrastructural changes of the peripheral nerve induced by vibration: an experimental study. Br J Ind Med 1989, 46:157-164.

42. Yan JG, Matloub HS, Sanger JR, Zhang LL, Riley DA: Vibration-induced disruption of retrograde axoplasmic transport in peripheral nerve. Muscle Nerve 2005, 32:521-526.

43. Loffredo MA, Yan JG, Kao D, Zhang LL, Matloub HS, Riley DA: Persistent reduction of conduction velocity and myelinated axon damage in vibrated rat tail nerves. Muscle Nerve 2009, 39:770-775.

44. Lundborg G, Dahlin LB, Hansson HA, Kanje M, Necking LE: Vibration exposure and peripheral nerve fiber damage. J Hand Surg [Am] 1990 15:346-351

45. Dahlin LB, Necking LE, Lundstrom R, Lundborg G: Vibration exposure and conditioning lesion effect in nerves: an experimental study in rats. $J$ Hand Surg [Am] 1992, 17:858-861.

46. Brammer AJ, Pyykko I: Vibration-induced neuropathy. Detection by nerve conduction measurements. Scand J Work Environ Health 1987, 13:317-322.

47. Brismar T, Ekenvall L: Nerve conduction in the hands of vibration exposed workers. Electroencephalogr Clin Neurophysiol 1992, 85:173-176.

48. Rolke R, Rolke S, Vogt T, Birklein F, Geber C, Treede RD, Letzel S, Voelter-Mahlknecht S: Hand-arm vibration syndrome: clinical characteristics, conventional electrophysiology and quantitative sensory testing. Clin Neurophysiol 2013, 124:1680-1688.

49. Hirata M, Sakakibara H: Sensory nerve conduction velocities of median ulnar and radial nerves in patients with vibration syndrome. Int Arch Occup Environ Health 2007, 80:273-280.

50. Sakakibara H, Hirata M, Hashiguchi T, Toibana N, Koshiyama H, Zhu SK, Kondo T, Miyao M, Yamada S: Digital sensory nerve conduction velocity and vibration perception threshold in peripheral neurological test for hand-arm vibration syndrome. Am J Ind Med 1996, 30:219-224.

51. Lander L, Lou W, House R: Nerve conduction studies and current perception thresholds in workers assessed for hand-arm vibration syndrome. Occup Med (Lond) 2007, 57:284-289.

52. Koskimies K, Farkkila M, Pyykko I, Jantti V, Aatola S, Starck J, Inaba R: Carpa tunnel syndrome in vibration disease. Br J Ind Med 1990, 47:411-416.

53. Thomsen NO, Rosen I, Dahlin LB: Neurophysiologic recovery after carpal tunnel release in diabetic patients. Clin Neurophysiol 2010, 121:1569-1573.

54. Cherniack M, Brammer AJ, Lundstrom R, Morse TF, Neely G, Nilsson T, Peterson D, Toppila E, Warren N, Diva U, Croteau M, Dussetschleger J: The effect of different warming methods on sensory nerve conduction velocity in shipyard workers occupationally exposed to hand-arm vibration. Int Arch Occup Environ Health 2008, 81:1045-1058.

55. Stalberg E, Falck B, Gilai A, Jabre J, Sonoo M, Todnem K: Standards for quantification of EMG and neurography. The international federation of clinical neurophysiology. Electroencephalogr Clin Neurophysiol Suppl 1999, 52:213-220.

56. Assmus H, Antoniadis G, Bischoff C, Haussmann P, Martini AK, Mascharka Z, Scheglmann K, Schwerdtfeger K, Selbmann HK, Towfigh H, Vogt T, Wessels KD, Wustner-Hofmann M: Diagnosis and therapy of carpal tunnel syndromeguideline of the German societies of handsurgery, neurosurgery, neurology, orthopaedics, clinical neurophysiology and functional imaging, plastic, reconstructive and aesthetic surgery, and surgery for traumatology. Handchir Mikrochir Plast Chir 2007, 39:276-288. 
57. Bostrom L, Gothe CJ, Hansson S, Lugnegard H, Nilsson BY: Surgical treatment of carpal tunnel syndrome in patients exposed to vibration from handheld tools. Scand J Plast Reconstr Surg Hand Surg 1994, 28:147-149.

58. Nishimura A, Ogura T, Hase H, Makinodan A, Hojo T, Katsumi Y, Yagi K, Kubo T: Evaluation of sensory function after median nerve decompression in carpal tunnel syndrome using the current perception threshold test. J Orthop Sci 2003, 8:500-504.

59. Wieslander G, Norback D, Gothe CJ, Juhlin L: Carpal tunnel syndrome (CTS) and exposure to vibration, repetitive wrist movements, and heavy manual work: a case-referent study. Br J Ind Med 1989, 46:43-47.

60. Rosen B, Chemnitz A, Weibull A, Andersson G, Dahlin LB, Bjorkman A: Cerebral changes after injury to the median nerve: a long-term follow up. J Plast Surg Hand Surg 2012, 46:106-112.

61. Taylor KS, Anastakis DJ, Davis KD: Cutting your nerve changes your brain. Brain 2009, 132:3122-3133.

doi:10.1186/1745-6673-9-7

Cite this article as: Dahlin et al: Low myelinated nerve-fibre density may lead to symptoms associated with nerve entrapment in vibration-induced neuropathy. Journal of Occupational Medicine and Toxicology 2014 9:7.

\section{Submit your next manuscript to BioMed Central and take full advantage of:}

- Convenient online submission

- Thorough peer review

- No space constraints or color figure charges

- Immediate publication on acceptance

- Inclusion in PubMed, CAS, Scopus and Google Scholar

- Research which is freely available for redistribution 